to have decided that these are exceedingly difficult questions which cannot be answered without study and experiment. Moreover, the President appears to have settled for a form of organization that will not disturb the present relations between the Office of Science and Technology at the White House and the National Science Foundation and the Department of Commerce, both of which have a finger in the pie of industrial innovation and development. So far, so good.

The biggest stumbling block in the years ahead is likely to be the difficulty of finding an alternative for the system for supporting industrial research and development in the United States which has been such a conspicuous success in recent decades. For the most part, the United States government has been able to forward the cause of industrial research and development in the United States by using its massive research and development programme in defence and space technology to provide a steady stream of development contracts. The result has been that companies large and small have been given not merely the funds needed to equip laboratories but also an incentive to develop particular products. With the inevitable decline of expenditure on defence and space, and with nuclear energy also running down, this source of funds is steadily diminishing. The question which the Administration has somehow to answer for itself is whether it will be feasible, in the years ahead, to create arrangements for stimulating research and development without this steady stream of project-oriented contracts. In short, the United States will have to develop systems for stimulating innovation which are very much like those much needed elsewhere in the world.

What, then, of the proposals put forward last week in the message on technology? The notion that the Department of Commerce should become the cornerstone of the Administration's intervention in private industry is sensible enough. Partly at least because of its control of the National Bureau of Standards, the department is well placed to play such a part. But political strength as well as cleverness will be needed if the department is somehow to avoid the difficulties which have bedevilled similar attempts elsewhere. What will happen, for example, if the aircraft industry, now unexpectedly falling on hard times, sets up a clamour for government assistance in research and development in much the spirit in which the American shipbuilding industry has been able to win subventions for itself? How rigorous will the Department of Commerce be in saying that its real concern is with innovation and not with the support of industries whose markets have, for one reason or another, become attenuated? By all accounts, the department has in mind a variety of schemes for setting up collaborative research projects, but here again there are lessons to be learned from experience elsewhere, especially in Britain. After all, nobody has been able to devise a way in which companies will pool their efforts in research without at the same time fearing that they will have put their commercial future in jeopardy. One of the consequences has been, in British experience, that larger members of research consortia always supplement the common programme with larger research programmes of their own. No doubt a large part of the trouble is that the research associations in Britain have been too securely institutionalized. The Department of Commerce might be better advised to encourage ad hoc arrangements for collaborative research.
The National Science Foundation's role in the new technology assistance framework is harder to define. Its chief efforts so far have been in encouraging closer collaboration between industry and the universities, sometimes with the help of matching grants. But the foundation also has its nose buried deeply on the trail of projects that will have some national importance. Its shopping list includes projects such as transport, the cleansing of the environment and the amelioration of earthquake damage. The trouble is that there is no easy relationship between these entirely desirable objectives and the future prosperity of the United States, which goes to show that it will be hard for anybody, Mr Magruder or the Department of Commerce, to base a continuing programme for the support of industrial innovation on the experience likely to be gathered by the National Science Foundation in the next few years. In short, the Administration has been wise to be cautious but, even so, it may not yet have realized the full magnitude of the task that it is attempting.

\section{Yeurs Ago}

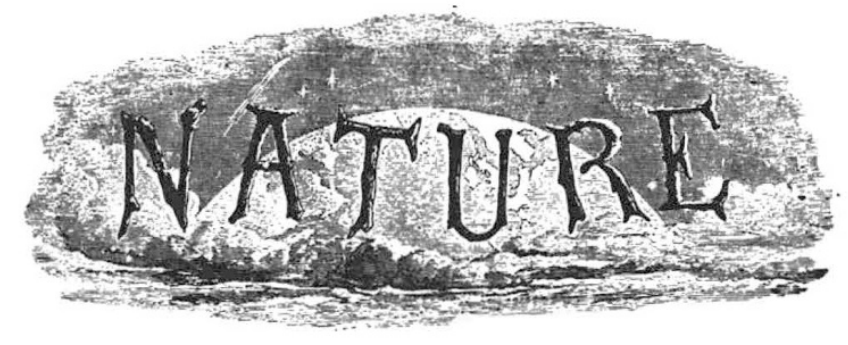

The Adamites

Philologists will notice with regret a paper bearing the above title in the late number of the Fournal of the Anthropological Institute. The author appears to have taken up, without proper study, that difficult and dangerous line of argument, the comparison of historical names, and has naturally fallen into the network of delusive fancy which in past generations entangled Jacob Bryant and Godfrey IHiggins. Modern philology has abundantly proved that slight, loose, and occasional correspon. dences in proper names are deceptive as evidence, even among languages of the same family, much more among languages of different families. It is a fair sample of the present paper, that it argues an affinity between the peoples of the (Old and New Worlds on the basis of a connection between various names of the Deity, among which are the Russian Bog, the Mantchoo $A 6-k a$, and the Hottentot Teqoa. The special purpose is to prove that nations are shown by their names to trace descent from an ancestor called $A d-$ " $A d a m$, or Father $A d$." Thus "the great Hamitic race of Akkad" is interpreted by the aid of Welsh ach-root, lineage," so as to mean "sons or lineage of Ad;" and the name of Ta-ata, the Polynesian First Man, is "that of the mythical ancestor of the Adamites, reversed, bowever, and with the addition of ata $(a k a)$, spirit"! It is obvious, though unaccountably overlooked in the paper, that two of the clearest cases of the theory may be found near home. The descent of two nations from Father Ad is perfectly recorded by ourselves, when we call the representative of one a Paddy, clearly $A p \cdot A d$ (from $A p$, " used in the sense of son"), while the other's Adamite ancestor is commemorated by calling his descendant a Ta.ffy.

It is not necessary to give the name of the author of this unlucky paper. Everybody is liable to slips, great or small; and a man may have done work worth doing in one line, but turning suddenly to another, may come to grief utterly. But the Council of the Anthropological Institute should have consulted their own interest and that of their contributor by declining to print the present essay. It is the duty of a learned society to examine even a hasty and ill-considered idea brought forward by one of its members, but not to put it on public record against themselves and him. 